\title{
O SISTEMA GLOBALMENTE HARMONIZADO DE CLASSIFICAÇÃO E ROTULAGEM DE PRODUTOS QUÍMICOS (GHS) - UMA INTRODUÇÃO PARA SUA APLICAÇÃO EM LABORATÓRIOS DE ENSINO E PESQUISA ACADÊMICA ${ }^{\dagger}$
}

\author{
Wilhelm Martin Wallau* e José Augusto dos Santos Júnior \\ Centro de Ciências Químicas, Farmacêuticas e de Alimentos, Universidade Federal de Pelotas, Campus Universitário, CP 354, \\ 96010-900 Pelotas - RS, Brasil
}

Recebido em 9/5/12; aceito em 1/10/12; publicado na web em 18/2/13

\begin{abstract}
THE GLOBALLY HARMONISED SYSTEM OF CLASSIFICATION, LABELLING AND PACKAGING OF CHEMICALS (GHS) - AN INTRODUCTION TO ITS APPLICATION IN ACADEMIC TEACHING AND RESEARCH LABORATORIES. The present article provides an overview of the Globally Harmonised System of Classification, Labelling and Packaging of Chemicals (GHS) and its implementation in Brazil. Although Classification and Packaging is beyond the scope of the responsibility of academic chemists, labelling of chemicals used in academic laboratories will be required by the competent authorities to ensure the safety of students and staff. Therefore, academic teachers and researchers responsible should be familiarised with the GHS principles outlined here and at least be able to label, by applying these principles, mixtures of substances previously classified by the competent authorities.
\end{abstract}

Keywords: GHS; laboratory safety; chemical education.

\section{INTRODUÇÃO}

Indiscutivelmente, a vida moderna por nós conhecida não seria possível sem o uso de produtos químicos em ampla escala, como mostraram as inúmeras contribuições durante o Ano Internacional de Química. ${ }^{1}$ Por outro lado, a Química possui outra face, representada por acidentes ambientais e danos à saúde humana, muitas vezes mais presentes na percepção da Química pelo público leigo. Embora os perigos desta outra faceta da Química já fossem conhecidos no século XIX, eram considerados como mal necessário para o progresso econômico ${ }^{2}$ e científico. $\mathrm{O}$ fato que até no nascimento do século XX se exigia nas universidades (alemãs) a habilidade de executar os trabalhos analíticos de casaca ${ }^{3}$ mostra a negligência com a proteção individual no meio acadêmico. Um dos autores ainda possui lembranças vivas como nos anos 80 , numa universidade alemã, os professores trataram os perigos à saúde humana com uma espécie de humor negro, explicando a falta de avisos toxicológicos com a "desculpa" de que até água em grandes quantidades poderia causar a morte por afogamento.

Com este "humor negro" dissimulavam sua carência de noções toxicológicas, cujo ensino não está presente nos cursos de Química. Assim, na maioria dos casos os perigos à saúde humana eram apontados por instituições externas, como mostra a proibição do uso de aceto arsenito de cobre(II) pelo governo alemão em 1887. ${ }^{4}$ Tais medidas singulares deram espaço para uma regulamentação geral nos anos 1960, resultado da observação de efeitos secundários do uso de agrotóxicos. ${ }^{5,6}$ Restritos aos agrotóxicos, os primeiros regulamentos sobre o uso de produtos químicos no Brasil ${ }^{7}$ não trouxeram efeito para os laboratórios acadêmicos e somente a partir de 1998, foi exigido que produtos químicos perigosos portem "informações essenciais sobre sua classificação, os perigos que oferecem e as precauções de segurança que devam ser observadas". ${ }^{8}$ O cumprimento dessa exigência legal é dificultado pelo fato de que se conhecem mais de 60 milhões de compostos químicos. ${ }^{9}$ Mesmo considerando que somente $1 \%$ desses compostos

In Memoriam Dr. iur. Horst-Günther Wallau (1932-2012)

*e-mail: martin_wallau@ufpel.edu.br são comercializados, ${ }^{10}$ a sua classificação ultrapassa a capacidade de um só país. Embora negligenciáveis do ponto de vista toxicológico, as diferenças entre os regulamentos nacionais requereriam a classificação dos produtos químicos separadamente em cada país para o qual seriam comercializados, ${ }^{11}$ assim dificultando o comércio internacional.

Em vista desses fatos, a Conferência das Nações Unidas sobre o Meio Ambiente e o Desenvolvimento recomendou o desenvolvimento de um Sistema Globalmente Harmonizado de classificação e rotulagem de produtos químicos (GHS - Globally Harmonised System).$^{5,6,11-13}$ Este sistema está não somente facilitando o comércio internacional, mas também se espera que sua aplicação aumente a segurança nos laboratórios acadêmicos. ${ }^{13}$

$\mathrm{O}$ intuito desse artigo é demonstrar a estrutura do GHS para o público acadêmico, muitas vezes adverso às exigências consideradas burocráticas, ou simplesmente intimidado pelo volume dos regulamentos, que na União Europeia (UE) ${ }^{14}$ chegam a quase 2000 páginas. Não é a intenção deste artigo explicar o processo de classificação em todos os detalhes, mas sim resumir o conteúdo das Normas e Regulamentos e ilustrar a estrutura do sistema GHS na classificação dos perigos inerentes, especialmente à saúde humana e ao meio ambiente, das substâncias puras e misturas utilizadas comumente nos laboratórios de ensino e pesquisa. As informações básicas contidas neste artigo devem permitir a classificação de soluções simples de substâncias perigosas ou, pelo menos, indicar os meios para se obter as informações necessárias para o processo de classificação. Tais conhecimentos podem contribuir significativamente na melhoria da segurança nos laboratórios de ensino e pesquisa nas universidades. Além disso, muitos estudantes, não somente de Química, como também de outros cursos, podem se confrontar, na sua vida profissional com o problema de classificar misturas e soluções de substâncias perigosas e necessitam para isso, pelo menos, de noções básicas do sistema GHS e como se pode obter informações sobre os perigos inerentes dessas substâncias.

\section{ESTRUTURA DO GHS}

Os princípios do GHS estão detalhados no "Livro Púrpura", ${ }^{15}$ editado pela United Nations Economic Commission for Europe, no 
qual os perigos são divididos nos três gêneros: Perigos Físicos, Perigos à Saúde Humana e Perigos ao Meio Ambiente que, por sua vez, são subdivididos em classes de perigos. Por exemplo, para os Perigos ao Meio Ambiente existem as três classes: Perigoso ao ambiente aquático - Agudo, Perigoso ao ambiente aquático - Crônico e Perigoso à camada de ozônio. ${ }^{14-16}$ Estas classes de perigo são, em geral, subdivididas em diversas categorias ou divisões. ${ }^{15,16} \mathrm{O}$ GHS, porém, não é uma norma legal e necessita a ratificação de sua adoção pelos estados singulares, bem como a criação de uma legislação nacional específica. Como este sistema abrange diversos setores, como segurança no transporte, proteção de trabalhadores, de consumidores e do meio ambiente, é estruturado de forma modular pelo "princípio de blocos de construção", ${ }^{17,18}$ possibilitando a adequação às diversas exigências. Devido à estrutura modular, a implementação do GHS pela legislação não exige que todos os módulos descritos no "Livro Púrpura" 15 sejam considerados, no entanto os elementos implementados pela legislação nacional não devem contrariar as normas do GHS. Para ilustrar este fato, algumas diferenças na aplicação realizada na Norma Brasileira ${ }^{16}$ e pelo Regulamento $\mathrm{UE}^{14}$ são apontados neste artigo.

\section{Indicação dos perigos dos produtos químicos no GHS}

\section{Elementos de rotulagem exigidos no GHS}

Segundo o GHS, ${ }^{15}$ a rotulagem de produtos químicos deve conter os seguintes itens, indicando os perigos inerentes e as medidas de prevenção adequadas pelos itens $2^{\circ}$ a $5^{\circ}$, explicados detalhadamente a seguir.

$1^{\circ}$ Identificação e composição do produto químico; $2^{\circ}$ Pictograma(s) de perigo; $3^{\circ}$ Palavra de advertência; $4^{\circ}$ Frase(s) de perigo; $5^{\circ}$ Frase(s) de precaução e $6^{\circ}$ Informações suplementares.

\section{Pictogramas de perigo}

Os pictogramas utilizados no GHS para indicar o perigo ${ }^{19}$ devem consistir em um símbolo preto, sobre um fundo branco dentro de um quadrado com borda vermelha apoiado num vértice. ${ }^{14,16}$ A Figura 1 mostra os pictogramas utilizados junto com o respectivo código ${ }^{14,17}$ e sua denominação segundo a Norma Brasileira. ${ }^{16}$ Observa-se que o símbolo GHS05 (Corrosão) indica tanto o perigo físico: Corrosivo para os metais, como os perigos para saúde: Corrosão à pele e Lesões oculares graves.

\section{Pictogramas para identificação de perigos físicos}

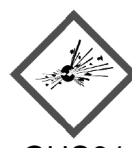

GHS01

Bomba explodindo

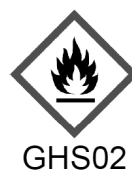

Chama

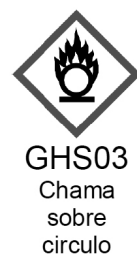

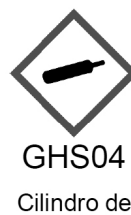

Cilindro de gás

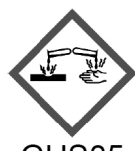

GHS05

Corrosão

\section{Pictogramas para identificação de perigos para saúde e do meio ambiente}
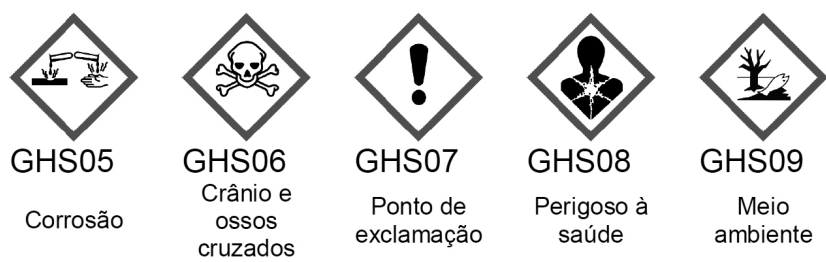

Figura 1. Pictogramas de perigo utilizadas no GHS com código e denominação ${ }^{16,17,19}$

\section{Palavras de advertência}

As palavras de advertência ${ }^{16}$ indicam o nível relativo da severidade do perigo inerente. A Norma Brasileira ${ }^{16}$ prevê o uso da palavra "PERIGO", equivalente a DANGER, para indicar os perigos mais severos, na maioria dos casos utilizados nas categorias de perigo $1 \mathrm{e}$ $2,{ }^{15}$ e o uso da palavra "ATENÇÃO”, equivalente a WARNING, para uma periculosidade menor.

\section{Frases de perigo}

As frases de perigo definidas no GHS ${ }^{15}$ são textos padronizados atribuídos às diversas classes e categorias de perigo que descrevem a natureza e, sendo apropriado, a severidade do perigo. Embora as frases de perigo devam ser padronizadas, encontram-se pequenas divergências nas traduções destas frases, definidas originalmente em inglês no GHS ${ }^{15}$ para o português aplicado pela Norma Brasileira ${ }^{16} \mathrm{e}$ pelo Regulamento da UE. ${ }^{14}$

Estas frases são identificadas por um código, que serve para referência, mas não faz parte da frase e nem deve ser utilizado para substituir a frase de perigo no rótulo de produtos perigosos. A estrutura do código das frases de perigo é ilustrada na Figura 2 e consiste na letra H, para indicação de Frase de perigo (Hazard Statement), um primeiro número indicando o gênero do perigo, conforme Figura 2, e dois números que correspondem à numeração sequencial dos perigos.

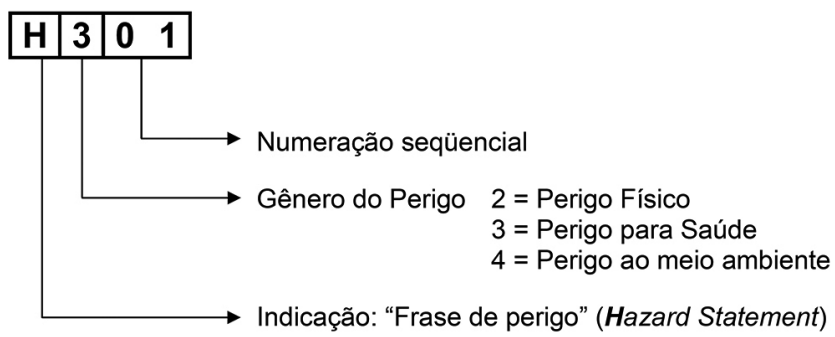

Figura 2. Codificação das frases de perigo no $G H S^{14-16}$

\section{Frases de precaução}

Como as Frases de perigo, as Frases de precaução são textos padronizados que descrevem as medidas recomendadas para evitar ou limitar os efeitos nocivos que podem ocorrer pelo uso ou pela exposição ao respectivo produto perigoso. Somente em caso de perigos de grande gravidade o número de frases de precaução na rotulagem do produto deve exceder o máximo de 6 frases. ${ }^{16,17}$ Semelhante às frases de perigo, as frases de precaução são identificadas por um código cuja estrutura é mostrada na Figura 3. Este código consiste na letra P, indicando frase de Precaução (Precautionary Statement), um primeiro número indicando o tipo de prevenção, conforme a indicação na Figura 3, e dois números sequenciais para indicação da medida. As frases de precaução recomendadas para cada categoria de perigo podem ser encontradas no Regulamento da UE, ${ }^{14}$ no $\mathrm{GHS}^{15}$ e na $2^{\mathrm{a}}$ edição da Norma Brasileira. ${ }^{16}$

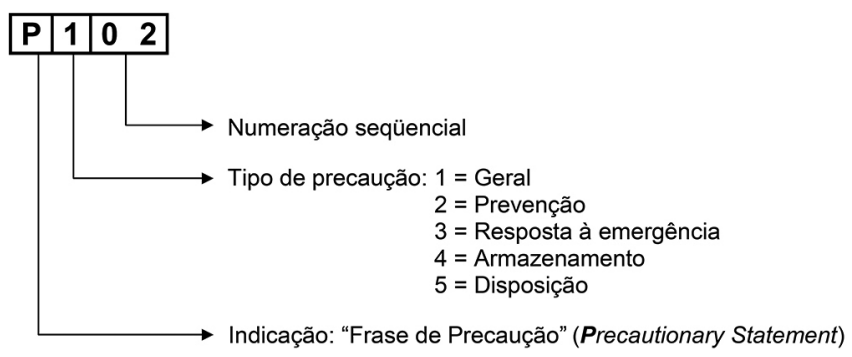


Um exemplo de um rótulo, conforme o GHS, é mostrado na Figura 4. Este rótulo foi elaborado com a ajuda de um aplicativo on-line e de livre acesso ${ }^{20}$ desenvolvido pela agência alemã de seguro público contra acidentes de trabalho na Indústria Química (Berufsgenossenschaft Rohstoffe und chemische Industrie) para ajudar empresas de porte pequeno ou médio na confecção dos rótulos e das Sicherheitsdatenblätter (Safety Data Sheets ou Fichas de Dados de Segurança). A maior desvantagem desse aplicativo não é que ele é oferecido somente em alemão, mas que é adaptado ao Regulamento da UE, ${ }^{14}$ a qual utiliza em alguns casos valores de concentração limite mais brandos e não considera todas as categorias de perigos implementadas na Norma Brasileira. ${ }^{16}$ Mesmo assim, para uso acadêmico, este aplicativo pode ser de grande utilidade e talvez possa servir como sugestão para o desenvolvimento de um aplicativo semelhante para as necessidades da Indústria Brasileira.

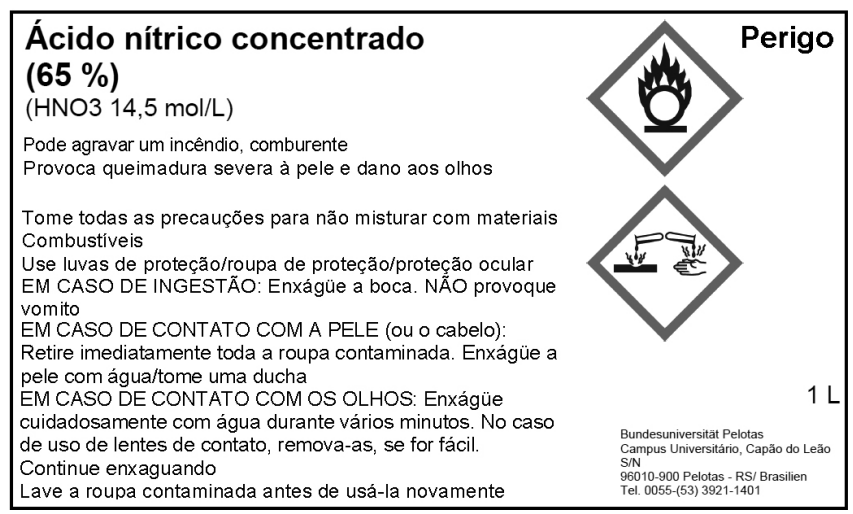

Figura 4. Exemplo para um rótulo conforme o GHS elaborado com o Gemischrechner ${ }^{20}$ (segundo a Norma Brasileira ${ }^{16}$ deve se incluir no rótulo ainda a Frase: "A Ficha de Informações de Segurança de Produtos Químicos deste produto químico perigoso pode ser obtida por meio de ...")

\section{IMPLEMENTAÇÃO DO GHS NO BRASIL}

Em 2007, foi instituído um Grupo de Trabalho Interministerial com a atribuição de coordenar a implementação do GHS no país ${ }^{21} \mathrm{e}$, em 2009, a ABNT publicou as Normas Brasileiras ABNT NBR 14725 partes $1-4,{ }^{16}$ que, baseadas no GHS, padronizam para os produtos químicos as informações sobre segurança, saúde e meio ambiente. Esta norma é obrigatória para classificação e rotulagem de substâncias puras desde 27/02/2011 e opcional para misturas até 31/05/2015, ${ }^{16,22}$ quando a classificação segundo o GHS será obrigatória para qualquer produto químico perigoso ou suas misturas.

Ressalta-se que, embora o Decreto 2657 de 03/07/1998 tenha promulgado a ratificação da Convenção 170 da Organização Internacional do Trabalho (OIT) de 1990, que obriga os estados assinantes a "estabelecer sistemas e critérios específicos apropriados para classificar todos os produtos químicos em função do tipo e do grau dos riscos físicos e para a saúde", ${ }^{8}$ bem como obriga que "os produtos químicos deverão portar, ainda, uma etiqueta ... que facilite informações essenciais sobre a sua classificação, os perigos que oferecem e as precauções de segurança que devam ser observadas", o GHS propriamente dito, que fornece os critérios de classificação e as exigências para rotulação e marcação de produtos químicos, não é formalmente ratificado pelo Brasil. O único documento legal que exige a aplicação do GHS no Brasil é a Norma Regulamentadora NR $26^{23}$ do Ministério do Trabalho e Emprego na redação dada pela Portaria SIT 229, de 24/05/2011. ${ }^{24}$ Esta Norma Reguladora sobre Sinalização de Segurança exige que a classificação "quanto aos perigos para a segurança e a saúde dos trabalhadores", ${ }^{23,24}$ a "rotulagem preventiva do produto químico classificado como perigoso"23,24 e "o formato e conteúdo da ficha com dados de segurança do produto químico" ${ }^{23,24}$ sigam "os critérios estabelecidos pelo Sistema Globalmente Harmonizado de Classificação e Rotulagem de Produtos Químicos (GHS)". ${ }^{23,24}$

\section{CLASSIFICAÇÃO DOS PERIGOS FÍSICOS NO GHS}

A Tabela 1 mostra as diversas classes e categorias dos perigos físicos, os pictogramas e as palavras de advertência atribuídos aos produtos químicos no GHS, ${ }^{15}$ junto com as respectivas frases de perigo segundo a Norma Brasileira. ${ }^{16}$ Instruções que explicam detalhadamente a classificação no GHS são publicadas em diversos países por seus órgãos oficiais. ${ }^{17,18,25-29}$

Para orientação geral, os métodos de classificação de produtos químicos são ilustrados por fluxogramas de decisão lógica ${ }^{14-16} \mathrm{e}$ os critérios detalhados dos métodos de teste adequados são descritos para os gases oxidantes na norma ISO 101156:2010, ${ }^{30} \mathrm{e}$ para as outras classes de perigos físicos, nas Recomendações da Organização das Nações Unidas (ONU) relativas ao Transporte de Mercadorias Perigosas, Manual de Ensaios e Critérios. ${ }^{31}$ A Tabela 2 mostra quais compostos necessitam da classificação nas diversas classes de perigos físicos, revelando que para algumas classes, somente compostos contendo elementos ou grupos funcionais específicos ou que possuam certos estados de confecção necessitam de classificação.

Atualmente, já existem diversas compilações de substâncias com suas classificações nos termos do GHS, como o Regulamento da UE, ${ }^{14}$ incluindo mais de 3300 substâncias, a classificação pelo National Institute of Technology and Evaluation do Japão, ${ }^{32}$ incluindo aproximadamente 1500 substâncias e as Recomendações da ONU relativas ao Transporte de Mercadorias Perigosas - RegulamentoTipo, ${ }^{33}$ incluindo os gases puros sob pressão. Segundo a legislação brasileira, ${ }^{8,23}$ estas listas podem ser aplicadas para classificar produtos químicos perigosos. Em geral, os perigos físicos de misturas devem ser classificados através de resultados experimentais. A Tabela 3, porém, lista para alguns líquidos oxidantes os valores de concentração de corte/limite para sua classificação, publicados no Regulamento da $\mathrm{UE},{ }^{14}$ que também podem servir como orientação para classificação dos sais desses ácidos e suas soluções.

\section{CLASSIFICAÇÃO DOS PERIGOS À SAÚDE HUMANA}

\section{Classificação de substâncias puras}

A Tabela 4 enumera as classes e categorias dos perigos à saúde humana com os elementos de indicação necessários para rotulagem segundo o GHS ${ }^{15}$ e a Norma Brasileira. ${ }^{16}$ Na classificação das substâncias, devem ser utilizados os métodos de ensaios padronizados, como aqueles elaborados pela Organisation for Economic Co-operation and Development (OECD). ${ }^{34}$ Porém, para a maioria das substâncias presentes nos laboratórios acadêmicos, a classificação dos perigos pode ser encontrada em compilações publicadas pela UE, ${ }^{14}$ pelo National Institute of Technology and Evaluation do Japão ${ }^{32}$ ou nas FISPQ, obrigatoriamente fornecidas pelo distribuidor, importador ou produtor de produtos químicos perigosos.

Controvérsias na classificação dos perigos para a saúde humana

Embora na classificação dos perigos à saúde humana sejam aplicados métodos padronizados, ${ }^{34}$ a interpretação dos resultados necessita da perícia de especialistas em toxicologia e farmacologia. As controvérsias na classificação de perigos à saúde humana são amplamente discutidas por Morita et al. ${ }^{35}$ especialmente para mutagenicidade. ${ }^{36}$ 
Tabela 1. Classes e categorias de perigos físicos com seus respectivos pictogramas, palavras de advertência e frases de perigo ${ }^{15,16}$

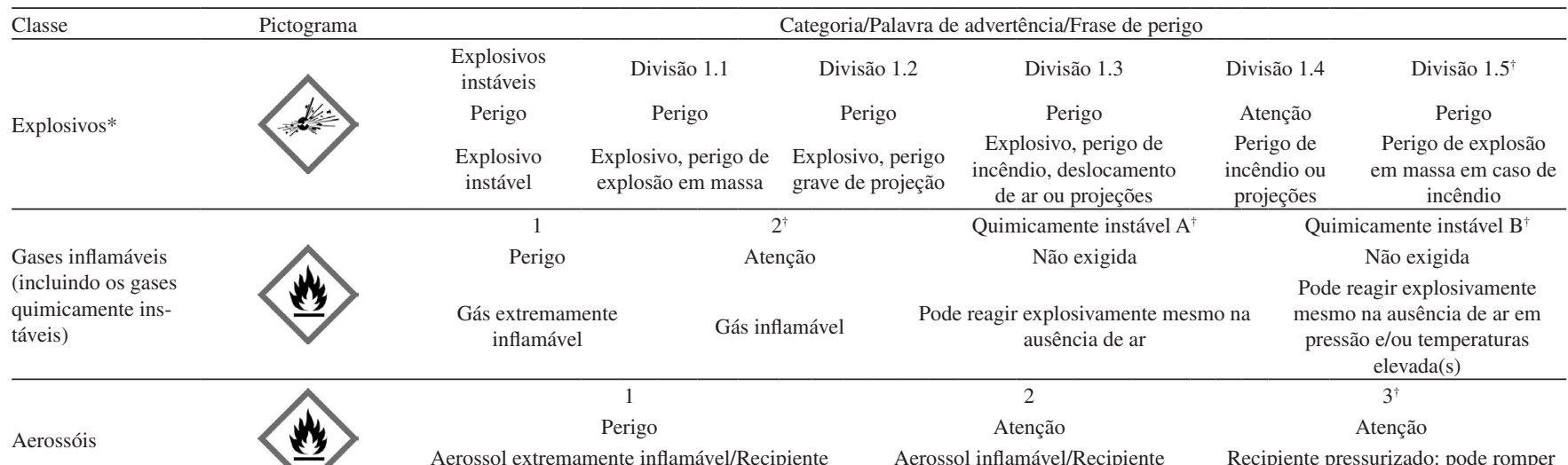
pressurizado: pode romper se aquecido pressurizado: pode romper se aquecido $\quad$ se aquecido

Gases oxidantes
Perigo
Pode provocar ou agravar um incêndio, oxidante

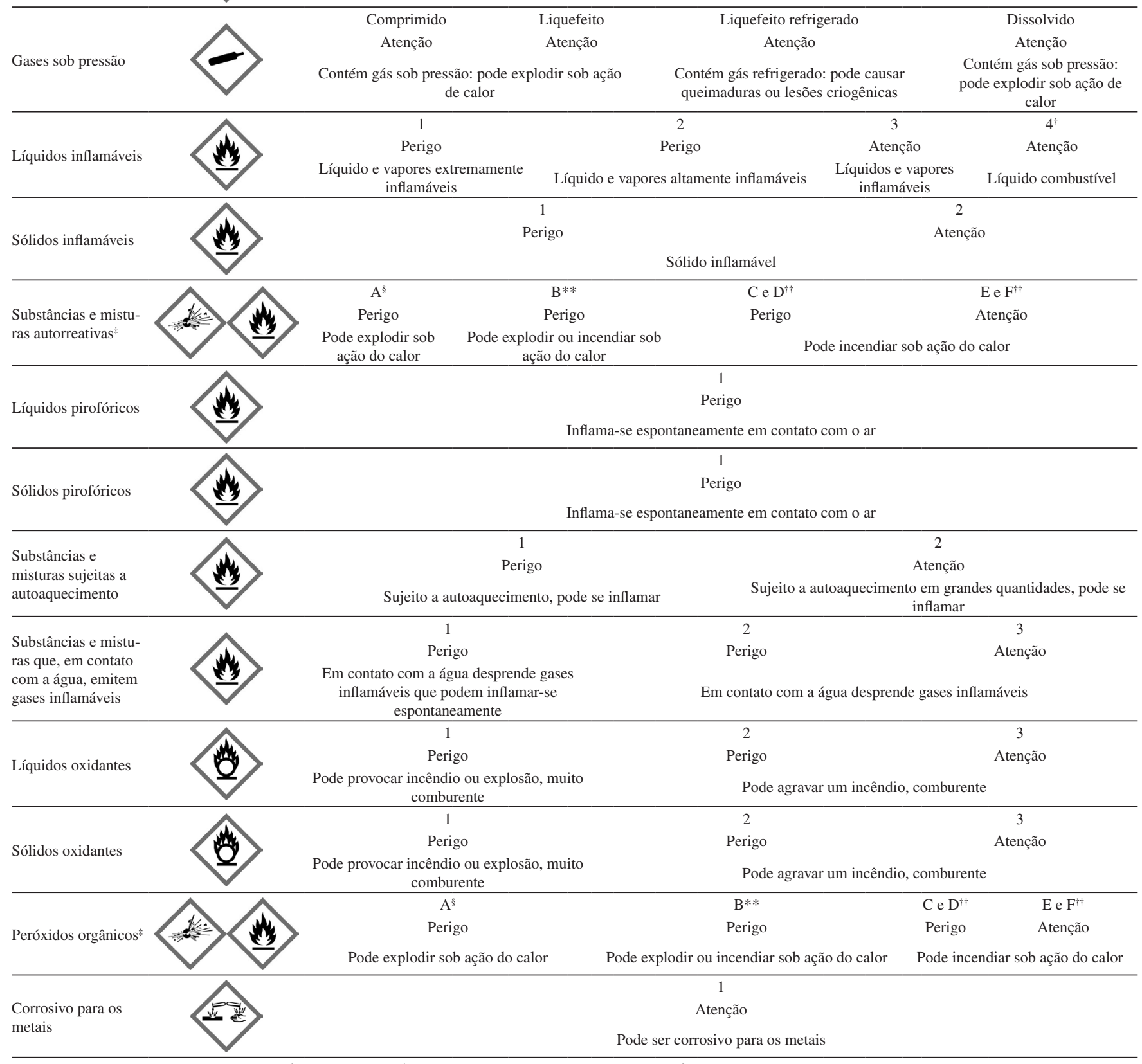

*existe divisão 1.6 sem indicação no rotulo; ${ }^{\dagger}$ sem pictograma; *existe categoria G sem indicação no rotulo; ${ }^{\S}$ somente Bomba explodindo como pictograma; **Bomba explodindo e Chama como pictograma; ${ }^{\dagger}$ somente Chama como pictograma. 
Tabela 2. Especificações para classificação dos perigos físicos de produtos químicos ${ }^{15}$

\begin{tabular}{|c|c|c|c|c|}
\hline \multirow{2}{*}{ Classe de Perigo Físico } & \multicolumn{4}{|r|}{ Compostos a classificar } \\
\hline & Gases & Líquidos & Sólidos & Especificação \\
\hline Explosivos & $\times$ & $\operatorname{sim}$ & $\operatorname{sim}$ & $\begin{array}{l}\text { Moléculas contendo: ligações -C-C- não saturadas; ligações } \\
\text { C-metal ou N-metal; átomos vizinhos ao nitrogênio; átomos } \\
\text { vizinhos ao oxigênio; ligação N-O; ligação N-halogênio; } \\
\text { ligação O-halogênio }\end{array}$ \\
\hline Gases inflamáveis & $\operatorname{sim}^{*}$ & $\times$ & $\times$ & $x$ \\
\hline Aerossóis & $\operatorname{sim}$ & $\operatorname{sim}$ & $\operatorname{sim}$ & $\times$ \\
\hline Gases oxidantes & $\operatorname{sim}$ & $\times$ & $\times$ & $\times$ \\
\hline Gases sob pressão & $\operatorname{sim}$ & $\times$ & $\times$ & $\times$ \\
\hline Líquidos inflamáveis & $\times$ & $\operatorname{sim}$ & $\times$ & $x$ \\
\hline Sólidos inflamáveis & $\times$ & $\times$ & $\operatorname{sim}$ & Substâncias: pulverizadas, granuladas ou pastosas \\
\hline Substâncias e misturas autorreativas & $\times$ & $\operatorname{sim}$ & $\operatorname{sim}$ & $\begin{array}{l}\text { Moléculas contendo: cross-reacting groups (Aminonitrilas, } \\
\text { haloanilinas, sais orgânicos de ácidos oxidantes); } \mathrm{S}=\mathrm{O} ; \mathrm{P}-\mathrm{O} \text {; } \\
\text { anéis tensionados; ligações não saturadas }\end{array}$ \\
\hline Líquidos pirofóricos & $\times$ & $\operatorname{sim}$ & $\times$ & $x$ \\
\hline Sólidos pirofóricos & $\times$ & $\times$ & $\operatorname{sim}$ & $\times$ \\
\hline Substâncias e misturas sujeitas a autoaquecimento & $\times$ & $\operatorname{sim}^{\dagger}$ & $\operatorname{sim}$ & $\times$ \\
\hline $\begin{array}{l}\text { Substâncias e misturas que, em contato com água, emitem } \\
\text { gases inflamáveis }\end{array}$ & $\times$ & $\operatorname{sim}$ & $\times$ & Compostos contendo: metais ou metalóides \\
\hline Líquidos oxidantes & $\times$ & $\operatorname{sim}$ & $\times$ & $\begin{array}{l}\text { Compostos contendo: Oxigênio, cloro ou flúor ligado a } \\
\text { elementos diferentes de carbono ou hidrogênio }\end{array}$ \\
\hline Sólidos oxidantes & $\times$ & $\times$ & $\operatorname{sim}$ & $\begin{array}{l}\text { Compostos contendo: Oxigênio, cloro ou flúor ligado a } \\
\text { elementos diferentes de carbono ou hidrogênio }\end{array}$ \\
\hline Peróxidos orgânicos & $\times$ & $\operatorname{sim}$ & $\operatorname{sim}$ & Compostos orgânicos contendo: "-O-O-“ \\
\hline Corrosivo para os metais & $\operatorname{sim}^{+}$ & $\operatorname{sim}$ & $\operatorname{sim}^{*}$ & $\times$ \\
\hline
\end{tabular}

*método de teste ISO 10156; ${ }^{1}{ }^{\dagger}$ método de teste somente designado para sólidos; ${ }^{\ddagger}$ método de teste somente designado para líquidos.

Tabela 3. Classificação de líquidos oxidantes encontrados em laboratórios de ensino e pesquisa segundo o Regulamento da UE ${ }^{14}$

\begin{tabular}{lcccl}
\hline \multirow{2}{*}{ Composto } & \multicolumn{2}{c}{ Concentração limite } & \multirow{2}{*}{ Categoria } & \multirow{2}{*}{ Frase de perigo } \\
\cline { 2 - 3 } Peróxido de hidrogênio & \multicolumn{1}{c}{ mol/L } & $\geq 26,15$ & 1 & Pode provocar incêndio ou explosão, comburente potente \\
& $50 \leq \mathrm{c}<70$ & $17,32 \leq \mathrm{c}<26,15$ & 2 & Pode agravar um incêndio, comburente \\
\hline \multirow{2}{*}{ Ácido perclórico } & $>50$ & $>6,35$ & 1 & Pode provocar incêndio ou explosão, comburente potente \\
& $\leq 50$ & $\leq 6,35$ & 2 & Pode agravar um incêndio, comburente \\
\hline Ácido nítrico & $\geq 65$ & $\geq 13,21$ & 3 & Pode agravar um incêndio, comburente \\
\hline
\end{tabular}

Uma fonte de erro na classificação pode ser a presença de impureza ou contaminante concomitantemente com o produto avaliado. Por exemplo, estireno foi originalmente classificado como cancerígeno (categoria 2), mas posteriormente as observações foram atribuídas à exposição concomitante ao butadieno ${ }^{35} \mathrm{e}$, atualmente, estireno não é mais classificado como cancerígeno. ${ }^{14,32}$ Devido à falta de perícia, a classificação dos perigos à saúde humana está além do horizonte dos químicos e nos laboratórios acadêmicos a classificação das substâncias puras deve se basear nas listas publicadas ${ }^{14,32,33}$ ou nas informações da respectiva FISPQ.

\section{Classificação de misturas}

\section{Classificação da toxicidade aguda baseada no princípio de aditividade}

A Tabela 5 mostra a classificação da toxicidade aguda. ${ }^{15,16}$ Enquanto na classificação de substâncias puras é usada, dependendo da via de ingestão, a dose ou a concentração letal $\left(\mathrm{DL}_{50}\right.$ ou $\left.\mathrm{CL}_{50}\right)$, a classificação de misturas é feita utilizando-se a estimativa da toxicidade aguda (ETA) enumerada para cada categoria de toxicidade aguda na Tabela 5. Assim, não há necessidade de conhecer para cada composto tóxico a sua respectiva dose ou concentração letal, e uma mistura é classificada pela $\mathrm{ETA}_{\text {mistura }}$ encontrada através da Equação
1 - Determinação da estimativa de toxicidade aguda (ETA) de misturas com toxicidade conhecida. ${ }^{14-17}$

$$
\frac{100}{E T A_{\text {mistura }}}=\sum_{i=1}^{n} \frac{c_{i}}{E T A_{i}}
$$

Em caso de misturas contendo substâncias de toxicidade desconhecida numa concentração acima de 10\%, a Equação 1 deve ser corrigida utilizando-se a Equação 2 - Determinação de ETA de misturas contendo $>10 \%$ de componentes com toxicidade desconhecida, ${ }^{14-17}$ ajustando-se assim a concentração dos componentes com toxicidade desconhecida $\left(c_{\mathrm{d}}\right) \cdot{ }^{14-17}$

$$
\frac{100-\left(\sum c_{d}\right)}{E T A_{\text {mistura }}}=\sum_{i=1}^{n} \frac{c_{i}}{E T A_{i}}
$$

Por exemplo, cianeto de potássio é classificado na categoria 1 para toxicidade aguda via contato com a pele, ${ }^{14}$ correspondendo a uma ETA de 5 (Tabela 5). Considerando a água como substância não tóxica, soluções aquosas de $10 ; 0,6 ; 0,45$ e $0,2 \%$, correspondendo a concentrações molares de 1,$53 ; 0,05 ; 0,07$ e $0,03 \mathrm{~mol} / \mathrm{L}$, e que possuem ETA $_{\text {mistura }}$ de 50, 300, 1100 e 2500, devem ser classificadas 
Tabela 4. Classes e categorias dos perigos para a saúde humana com os pictogramas, palavras de advertência e frases de perigo atribuídos ${ }^{15,16}$

\begin{tabular}{|c|c|c|c|c|c|c|c|c|}
\hline \multirow{2}{*}{$\frac{\text { Classe }}{\text { Categoria }}$} & \multicolumn{5}{|c|}{ Toxicidade aguda } & \multicolumn{3}{|c|}{$\begin{array}{l}\text { Mutagenicidade em células germinativas/ } \\
\text { Carcinogenicidade/Toxicidade à reprodução }\end{array}$} \\
\hline & 1 & 2 & 3 & 4 & 5 & $1 \mathrm{~A}$ & $1 \mathrm{~B}$ & 2 \\
\hline \multicolumn{9}{|l|}{ Pictograma } \\
\hline $\begin{array}{l}\text { Palavra de } \\
\text { advertência }\end{array}$ & Perigo & Perigo & Perigo & Atenção & Atenção & Perigo & Perigo & Atenção \\
\hline Frase de perigo ${ }^{16}$ & $\begin{array}{l}\text { Fatal se } \\
\text { ingerido* }\end{array}$ & $\begin{array}{l}\text { Fatal se } \\
\text { ingerido* }\end{array}$ & Tóxico se ingerido* & $\begin{array}{l}\text { Nocivo se } \\
\text { ingerido* }\end{array}$ & $\begin{array}{l}\text { Pode ser nocivo } \\
\text { se ingerido* }\end{array}$ & $\begin{array}{c}\text { Pode provocar } \\
\text { defeitos } \\
\text { genéticos } \\
\end{array}$ & $\begin{array}{c}\text { Pode provocar } \\
\text { defeitos } \\
\text { genéticos }^{\dagger}\end{array}$ & $\begin{array}{c}\text { Suspeito de } \\
\text { provocar defeitos } \\
\text { genéticos } \\
\end{array}$ \\
\hline Classe & \multicolumn{5}{|c|}{ Corrosão/irritação à pele } & \multicolumn{3}{|c|}{ Lesões oculares graves/irritação ocular } \\
\hline Categoria & $1 \mathrm{~A}$ & 1B & $1 \mathrm{C}$ & 2 & 3 & 1 & $2 \mathrm{~A}$ & $2 \mathrm{~B}$ \\
\hline Pictograma & & & & & - & & & - \\
\hline $\begin{array}{l}\text { Palavra de } \\
\text { advertência }\end{array}$ & Perigo & Perigo & Perigo & Atenção & Atenção & Perigo & Atenção & Atenção \\
\hline
\end{tabular}

\begin{tabular}{|c|c|c|c|c|c|c|c|c|}
\hline advertência & Perigo & Perigo & Perigo & Atenção & Atenção & Perigo & Atenção & Atenção \\
\hline Frase de perigo ${ }^{16}$ & $\begin{array}{c}\text { Provoca } \\
\text { queimadura } \\
\text { severa à pele e } \\
\text { dano aos olhos }\end{array}$ & $\begin{array}{c}\text { Provoca } \\
\text { queimadura } \\
\text { severa à pele e } \\
\text { dano aos olhos }\end{array}$ & $\begin{array}{c}\text { Provoca } \\
\text { queimadura } \\
\text { severa à pele e } \\
\text { dano aos olhos }\end{array}$ & $\begin{array}{c}\text { Provoca } \\
\text { irritação à pele }\end{array}$ & $\begin{array}{l}\text { Provoca irritação } \\
\text { moderada à pele }\end{array}$ & $\begin{array}{l}\text { Provoca danos } \\
\text { oculares graves }\end{array}$ & $\begin{array}{c}\text { Provoca } \\
\text { irritação ocular } \\
\text { séria }\end{array}$ & $\begin{array}{c}\text { Provoca irritação } \\
\text { ocular }\end{array}$ \\
\hline
\end{tabular}

Classe Toxicidade para órgãos-alvo específicos - Exposição única $\quad$ Sensibilização $\quad$ Toxicidade para órgãos-alvo específicos -

\begin{tabular}{|c|c|c|c|c|c|c|c|}
\hline Categoria & 1 & 2 & 3 & $\begin{array}{c}\text { respiratória } \\
\text { (categoria } 1 \mathrm{~A} \text { e } \mathrm{B} \text { ) }\end{array}$ & $\begin{array}{c}\text { à pele (categoria } \\
1 \mathrm{~A} \text { e } \mathrm{B})\end{array}$ & 1 & 2 \\
\hline \multicolumn{8}{|l|}{ Pictograma } \\
\hline $\begin{array}{l}\text { Palavra de } \\
\text { advertência }\end{array}$ & Perigo & Atenção & Atenção & Perigo & Atenção & Perigo & Atenção \\
\hline $\begin{array}{l}\text { Frase de } \\
\text { perigo }^{16}\end{array}$ & $\begin{array}{l}\text { Provoca danos aos } \\
\text { órgãos } \ldots{ }^{\S} \mathrm{se} \ldots * *\end{array}$ & $\begin{array}{c}\text { Pode provocar } \\
\text { danos aos órgãos } \\
\quad \ldots{ }^{\S} \text { se } \ldots * *\end{array}$ & $\begin{array}{l}\text { Pode provocar } \\
\text { irritação das vias } \\
\text { respiratórias/ } \\
\text { Pode provocar } \\
\text { sonolência e } \\
\text { vertigem }\end{array}$ & $\begin{array}{l}\text { Quando inalado } \\
\text { pode provocar } \\
\text { sintomas } \\
\text { alérgicos, de asma } \\
\text { ou dificuldades } \\
\text { respiratórias }\end{array}$ & $\begin{array}{c}\text { Pode provocar } \\
\text { reações alérgicas } \\
\text { na pele }\end{array}$ & $\begin{array}{c}\text { Provoca danos } \\
\text { aos órgãos ... }{ }^{\S} \text { por } \\
\text { exposição repetida } \\
\text { ou prolongada**,† }{ }^{*}+\end{array}$ & $\begin{array}{l}\text { Pode provocar danos } \\
\text { aos órgãos ... }{ }^{\S} \text { por } \\
\text { exposição repetida } \\
\text { ou prolongada**,† }\end{array}$ \\
\hline
\end{tabular}

*Para toxicidade oral; para toxicidade dérmica substitua "se ingerido" por "em contato com a pele"; e toxicidade por inalação substitua "ingerido" por "inalado"; "para Mutagenicidade em células germinativas; para Carcinogenicidade substitua "defeitos genéticos" por "câncer"; para Toxicidade à reprodução: categoria 1A e 1B usa frase de perigo: "Pode prejudicar a fertilidade ou o feto", categoria 2 "Suspeita-se que prejudique a fertilidade ou o feto". *Para Toxicidade à reprodução existe categoria adicional para efeitos sobre ou via lactação indicado somente pela frase de perigo: "Pode ser nocivo às crianças alimentadas com leite materno"; sem pictograma e palavra de advertência atribuída. ${ }^{\S}$ Descrever todos os órgãos afetados, se conhecidos; **Descrever a via de exposição se for provado que não há outras vias de exposição que causem perigo. ${ }^{\dagger}$ Para toxicidade para órgãos-alvo específicos - Exposição repetida; para Perigo por aspiração categoria 1 usa frase de perigo: "Pode ser fatal se ingerido e penetrar nas vias respiratórias"; categoria 2 usa frase de perigo: "Pode ser nocivo se ingerido e penetrar nas vias respiratórias".

Tabela 5. Valores limites $\mathrm{DL}_{50} / \mathrm{CL}_{50}$ e estimativa da toxicidade aguda (ETA) para classificação da toxicidade aguda ${ }^{15,16}$

\begin{tabular}{|c|c|c|c|c|c|c|c|c|c|c|}
\hline \multirow{3}{*}{ Via de exposição } & \multicolumn{10}{|c|}{ Limites superiores e ETA } \\
\hline & \multicolumn{2}{|c|}{ Categoria 1} & \multicolumn{2}{|c|}{ Categoria 2} & \multicolumn{2}{|c|}{ Categoria 3} & \multicolumn{2}{|c|}{ Categoria 4} & \multicolumn{2}{|c|}{ Categoria 5} \\
\hline & $\mathrm{DL}_{50} / \mathrm{CL}_{50}$ & ETA & $\mathrm{DL}_{50} / \mathrm{CL}_{50}$ & ETA & $\mathrm{DL}_{50} / \mathrm{CL}_{50}$ & ETA & $\mathrm{DL}_{50} / \mathrm{CL}_{50}$ & ETA & $\mathrm{DL}_{50} / \mathrm{CL}_{50}$ & ETA \\
\hline Oral (mg/kg peso corpóreo) & 5 & 0,5 & 50 & 5 & 300 & 100 & 2000 & 500 & & 2500 \\
\hline Dérmica (mg/kg peso corpóreo) & 50 & 5 & 200 & 50 & 1000 & 300 & 2000 & 1100 & & 2500 \\
\hline Gases $(\mu 1 / L ; p p m)$ & 100 & 10 & 500 & 50 & 2500 & 700 & 5000 & 3000 & 5000 & - \\
\hline Vapores (mg/L) & 0,5 & 0,05 & 2,0 & 0,5 & 10 & 3 & 20 & 11 & & - \\
\hline Poeiras e névoas (mg/L) & 0,05 & 0,005 & 0,5 & 0,05 & 1,0 & 0,5 & 5 & 1,5 & & - \\
\hline
\end{tabular}

para toxicidade aguda via contato com a pele nas categorias $2,3,4$ e 5 , respectivamente.

\section{Classificação da corrosão/irritação à pele e lesões oculares graves/irritação ocular}

A Tabela 6 mostra as concentrações somatórias aplicadas na classificação de misturas corrosivas ou irritantes à pele e causadoras de lesões oculares graves ou irritação ocular, segundo o GHS ${ }^{15}$ e a Norma Brasileira. ${ }^{16}$ Por exemplo, classificam-se misturas de triclorossilano, classificado na categoria 1 $\mathrm{A}^{14,32}$ (Provoca queimadura severa à pele $\mathrm{e}$ dano aos olhos) da classe Corrosão/irritação à pele, em um solvente como etilbenzeno, classificado na categoria 3 (Provoca irritação moderada à pele) dessa classe, com a ajuda da Tabela 6 da seguinte maneira: para concentrações $\geq 0,324 \mathrm{~mol} / \mathrm{L}$ ( $\geq 5 \%$ ), a solução de $\mathrm{SiHCl}_{3}$ em etilbenzeno será classificada como a substância pura na categoria $1 \mathrm{~A}$, e concentrações entre $0,324 \mathrm{~mol} / \mathrm{L}>\mathrm{c} \geq 0,065 \mathrm{~mol} / \mathrm{L}$ $(5 \%>c \geq 1 \%)$ na categoria 2 (Provoca irritação à pele). Para uma concentração de $\mathrm{SiHCl}_{3}<0,065 \mathrm{~mol} / \mathrm{L}$ a mistura é classificada como 
Tabela 6. Concentração de componentes de uma mistura para classificação corrosão/irritação à pele e lesões oculares graves/irritação ocular15-17

\begin{tabular}{|c|c|c|c|}
\hline \multirow{3}{*}{$\begin{array}{l}\text { Soma das concentrações classificadas nas categorias } \\
\text { Efeitos cutâneos }\end{array}$} & \multicolumn{3}{|c|}{ Concentração limitante para classificação } \\
\hline & \multirow{2}{*}{$\begin{array}{c}\text { Corrosivo } \\
\text { Categoria } 1 \mathrm{~A}, \mathrm{~B} \text { ou } \mathrm{C}^{*}\end{array}$} & \multicolumn{2}{|c|}{ Irritante } \\
\hline & & Categoria 2 & Categoria 3 \\
\hline Categoria 1 cutânea & $\geq 5 \%$ & $1 \% \leq \mathrm{c}<5 \%$ & - \\
\hline Categoria 2 & - & $\geq 10 \%$ & $1 \% \leq \mathrm{c}<10 \%$ \\
\hline Categoria 3 cutânea & & & $\geq 10 \%$ \\
\hline$(10 \times$ categoria 1 cutânea $)+$ categoria 2 cutânea & & $\geq 10 \%$ & $1 \% \leq \mathrm{c}<10 \%$ \\
\hline$(10 \times$ categoria 1 cutânea $)+$ categoria 2 cutânea + categoria 3 cutânea & & & $\geq 10 \%$ \\
\hline \multirow{2}{*}{ Efeitos oculares } & Lesivo & & Irritante \\
\hline & Categoria 1 & & Categoria $2 \mathrm{~A}$ ou B \\
\hline Categoria 1 ocular ou cutânea & $\geq 3 \%$ & & $1 \% \leq \mathrm{c}<3 \%$ \\
\hline Categoria 2 ocular ou cutânea & - & & $\geq 10 \%$ \\
\hline$(10 \times$ categoria 1$)$ ocular $+($ categoria 2 ocular + categoria 2 cutânea $)$ & - & & $\geq 10 \%$ \\
\hline Categoria 1 cutânea + categoria 1 ocular & $\geq 3 \%$ & & $1 \% \leq \mathrm{c}<3 \%$ \\
\hline $10 \times($ Categoria 1 cutânea + categoria 1 ocular $)+$ categoria 2 ocular & - & & $\geq 10 \%$ \\
\hline
\end{tabular}

*Nos casos de subcategorias para a categoria 1, a soma de todos os componentes de uma mistura classificada como categorias $1 \mathrm{~A}, 1 \mathrm{~B}$ ou $1 \mathrm{C}$, respectivamente, deve ser individualmente $>5 \%$ para classificar a mistura como categorias $1 \mathrm{~A}, 1 \mathrm{~B}$ ou $1 \mathrm{C}$. No caso da soma dos componentes da categoria $1 \mathrm{~A}$ para pele ser $<5 \%$, mas a soma dos componentes das categorias $1 \mathrm{~A}+1 \mathrm{~B}$ para a pele ser $\geq 5 \%$, a mistura deve ser classificada como categoria $1 \mathrm{~B}$ para pele. Da mesma maneira, no caso da soma das categorias $1 \mathrm{~A}+1 \mathrm{~B}$ ser $<5 \%$, mas a soma das categorias $1 \mathrm{~A}+1 \mathrm{~B}+1 \mathrm{C}$ para pele ser $\geq 5 \%$, a mistura pode ser classificado como categoria $1 \mathrm{C}$.

o solvente puro na categoria 3, segundo a Norma Brasileira. ${ }^{16}$ Como o Regulamento da UE ${ }^{14}$ não considera na classe Corrosão/irritação à pele a categoria 3 , tanto para o solvente puro como para a mistura com uma concentração de $\mathrm{SiHCl}_{3}<0,065 \mathrm{~mol} / \mathrm{L}$, a classificação de perigo é dispensada nessa classe pelo Regulamento da UE. ${ }^{14}$

Ressalta-se, porém, que a classificação de certos tipos de substâncias nas classes corrosão/irritação à pele e lesões/irritação oculares não pode ser possível à base da abordagem aditiva, ilustrada no parágrafo anterior. ${ }^{14-17}$ Soluções dessas substâncias, como ácidos e bases, sais inorgânicos, aldeídos, fenóis e surfactantes, que são classificadas na categoria 1 dessas classes, também devem ser classificadas nessa categoria se a sua concentração for maior ou igual a $1 \%$, ou em caso de ácidos e bases, se a mistura possui um valor de $\mathrm{pH} \leq 2$ ou $\geq 11,5$. $^{14-17}$ Se uma substância é classificada na categoria 2 das classes corrosão/ irritação à pele e lesões/irritação oculares, as misturas contendo essas substâncias também devem ser classificadas nessa categoria se a soma de suas concentrações for maior ou igual a $3 \% .^{14-17}$

Por outro lado, o Regulamento da UE, ${ }^{14} \mathrm{em}$ conformidade com o GHS, ${ }^{15}$ esclarece na subdivisão 3.2.2.1, que "a análise deverá partir dos dados e experiências com seres humanos e animais de exposições únicas ou repetidas, visto ambos darem directamente informações acerca dos efeitos". O Regulamento da UE ${ }^{14}$ estabeleceu, a partir de tais experiências, para alguns ácidos e bases praticamente onipresentes em laboratórios de ensino e pesquisa, os valores de corte/limite para esta classificação, que são mostrados na Tabela 7.

Classificação de misturas em respeito à mutagenicidade em células germinativas, carcinogenicidade, toxicidade à reprodução, sensibilização respiratória e à pele, toxicidade para órgãos-alvo específicos (TOAE) e perigo por aspiração

A Tabela 8 mostra, para as classes mutagenicidade em células germinativas, carcinogenicidade, toxicidade à reprodução e lactação, sensibilização respiratória, sensibilização à pele, toxicidade para órgãos-alvo específicos (TOAE) e perigo por aspiração, as respectivas concentrações de corte/limite para classificação de misturas estabelecidas na Norma Brasileira. ${ }^{16}$ Com exceção das classes mutagenicidade em células germinativas e perigo por aspiração, o $\mathrm{GHS}^{15}$ deixa para o parecer da autoridade local competente estabelecer os limites de corte dentro de uma faixa definida. Assim, o Regulamento da $\mathrm{UE}^{14}$ adotou os valores de corte/limite mais brandos, enumerados também na Tabela 8.
Tabela 7. Classificação dos perigos cutâneos e oculares de ácidos e bases frequentemente utilizados em laboratórios de ensino e pesquisa, como estabelecida no Regulamento da $\mathrm{UE}^{14}$

\begin{tabular}{|c|c|c|c|c|}
\hline Compostos & Classe & Categoria & $\begin{array}{c}\text { Concentração } \\
(\%)\end{array}$ & $\begin{array}{c}\text { Concentração } \\
(\mathrm{mol} / \mathrm{L})\end{array}$ \\
\hline \multirow{3}{*}{$\mathrm{H}_{2} \mathrm{SO}_{4}$} & \multirow{2}{*}{ Cutânea } & $1 \mathrm{~A}$ & $\geq 15$ & $\geq 1,69$ \\
\hline & & 2 & $5 \leq c<15$ & $0,53 \leq \mathrm{c}<1,69$ \\
\hline & Ocular & 2 & $5 \leq \mathrm{c}<15$ & $0,53 \leq \mathrm{c}<1,69$ \\
\hline \multirow{3}{*}{$\mathrm{HCl}$} & \multirow{2}{*}{ Cutânea } & 1B & $\geq 25$ & $\geq 7,71$ \\
\hline & & 2 & $10 \leq \mathrm{c}<25$ & $2,87 \leq \mathrm{c}<7,71$ \\
\hline & Ocular & 2 & $10 \leq \mathrm{c}<25$ & $2,87 \leq \mathrm{c}<7,71$ \\
\hline \multirow{3}{*}{$\mathrm{H}_{3} \mathrm{PO}_{4}$} & \multirow{2}{*}{ Cutânea } & 1B & $\geq 25$ & $\geq 2,93$ \\
\hline & & 2 & $10 \leq \mathrm{c}<25$ & $1,08 \leq \mathrm{c}<2,93$ \\
\hline & Ocular & 2 & $10 \leq \mathrm{c}<25$ & $1,08 \leq \mathrm{c}<2,93$ \\
\hline \multirow{2}{*}{$\mathrm{HNO}_{3}$} & \multirow{2}{*}{ Cutânea } & $1 \mathrm{~A}$ & $\geq 20$ & $\geq 3,54$ \\
\hline & & 1B & $5 \leq \mathrm{c}<20$ & $0,81 \leq \mathrm{c}<3,54$ \\
\hline \multirow{4}{*}{$\begin{array}{l}\text { Ácido } \\
\text { fórmico }\end{array}$} & \multirow{3}{*}{ Cutânea } & $1 \mathrm{~A}$ & $\geq 90$ & $\geq 23,34$ \\
\hline & & 1B & $25 \leq \mathrm{c}<90$ & $5,76 \leq \mathrm{c}<23,34$ \\
\hline & & 2 & $2 \leq \mathrm{c}<25$ & $0,44 \leq \mathrm{c}<5,76$ \\
\hline & Ocular & 2 & $2 \leq \mathrm{c}<25$ & $0,44 \leq \mathrm{c}<5,76$ \\
\hline \multirow{4}{*}{$\begin{array}{l}\text { Acido } \\
\text { acético }\end{array}$} & \multirow{3}{*}{ Cutânea } & $1 \mathrm{~A}$ & $\geq 90$ & $\geq 15,95$ \\
\hline & & 1B & $25 \leq \mathrm{c}<90$ & $4,29 \leq \mathrm{c}<90$ \\
\hline & & 2 & $10 \leq \mathrm{c}<25$ & $1,69 \leq \mathrm{c}<4,29$ \\
\hline & Ocular & 2 & $10 \leq \mathrm{c}<25$ & $1,69 \leq \mathrm{c}<4,29$ \\
\hline \multirow{4}{*}{$\mathrm{NaOH}$} & \multirow{3}{*}{ Cutânea } & $1 \mathrm{~A}$ & $\geq 5$ & $\geq 1,32$ \\
\hline & & 1B & $2 \leq \mathrm{c}<5$ & $0,51 \leq \mathrm{c}<1,32$ \\
\hline & & 2 & $0,5 \leq \mathrm{c}<2$ & $0,13 \leq \mathrm{c}<0,51$ \\
\hline & Ocular & 2 & $0,5 \leq \mathrm{c}<2$ & $0,13 \leq \mathrm{c}<0,51$ \\
\hline \multirow{4}{*}{$\mathrm{KOH}$} & \multirow{3}{*}{ Cutânea } & $1 \mathrm{~A}$ & $\geq 5$ & $\geq 0,93$ \\
\hline & & 1B & $2 \leq \mathrm{c}<5$ & $0,36 \leq \mathrm{c}<0,93$ \\
\hline & & 2 & $0,5 \leq \mathrm{c}<2$ & $0,09 \leq \mathrm{c}<0,36$ \\
\hline & Ocular & 2 & $0,5 \leq \mathrm{c}<2$ & $0,09 \leq \mathrm{c}<0,36$ \\
\hline
\end{tabular}

Por outro lado, o GHS ${ }^{15}$ admite que para as classes de sensibilização respiratória, sensibilização à pele, mutagenicidade em células germinativas, carcinogenicidade, toxicidade à reprodução e TOAE, na classificação, sejam utilizados os dados de ensaios e experiências 
Tabela 8. Concentrações de corte/limite segundo a Norma Brasileira e o Regulamento da UE para as classes de perigos para a saúde humana onde não se aplica o princípio da aditividade

\begin{tabular}{lcc}
\hline \multirow{2}{*}{ Classe/Categoria } & \multicolumn{2}{c}{ Concentração de corte/limite } \\
\cline { 2 - 3 } & $\begin{array}{c}\text { Norma } \\
\text { Brasileira }\end{array}$ & $\begin{array}{c}\text { Regulamento } \\
\text { UE }^{14}\end{array}$ \\
\hline $\begin{array}{l}\text { Sensibilização respiratória/categoria } \\
1 \text { (sólidos/líquidos) }\end{array}$ & $\geq 0,1 \%$ & $\geq 1 \%$ \\
$\begin{array}{l}\text { Sensibilização respiratória/categoria } \\
1 \text { (gases) }\end{array}$ & $\geq 0,1 \%$ & $\geq 0,2 \%$ \\
\hline Sensibilização à pele/categoria 1 & $\geq 0,1 \%$ & $\geq 1 \%$ \\
\hline Mutagenicidade/categoria 1A ou 1B & $\geq 0,1 \%$ & $\geq 0,1 \%$ \\
Mutagenicidade/categoria 2 & $\geq 1 \%$ & $\geq 1 \%$ \\
\hline Carcinogenidade/categoria 1A ou 1B & $\geq 0,1 \%$ & $\geq 0,1 \%$ \\
Carcinogenidade/categoria 2 & $\geq 0,1 \%$ & $\geq 1 \%$ \\
\hline $\begin{array}{l}\text { Toxicidade reprodutiva/categoria } \\
\text { 1A ou 1B }\end{array}$ & $\geq 0,1 \%$ & $\geq 0,3 \%$ \\
$\begin{array}{l}\text { Toxicidade reprodutiva/categoria 2 } \\
\text { Toxicidade reprodutiva -Efeitos sobre } \\
\text { ou via lactação }\end{array}$ & $\geq 0,1 \%$ & $\geq 3 \%$ \\
\hline $\begin{array}{l}\text { TOAE* - Exposição única/Categoria } \\
\text { 1 ou 2 }\end{array}$ & $\geq 1 \%$ & $\geq 0,3 \%$ \\
$\begin{array}{l}\text { TOAE* - Exposição repetida/Catego- } \\
\text { ria 1 ou 2 }\end{array}$ & $\geq 1 \%$ & $\geq 10 \%$ \\
Perigo por aspiração/Categoria 1 ou 2 & $\geq 10 \%$ & $\geq 10 \%$ \\
\hline
\end{tabular}

*Toxicidade para órgãos-alvo específicos; ${ }^{\dagger}$ com viscosidade cinemática à $40{ }^{\circ} \mathrm{C} \leq 20,5 \mathrm{~mm}^{2} / \mathrm{s}$ para categoria $1 \mathrm{ou} \leq 14 \mathrm{~mm}^{2} / \mathrm{s}$ para categoria 2.

sobre as misturas numa base caso-a-caso. A partir de tais dados, o Regulamento da $\mathrm{UE}^{14}$ classifica algumas substâncias nessas classes aplicando concentrações abaixo dos respectivos valores de corte/ limite enumerados na Tabela 8. Algumas substâncias, classificados pela UE com valores de corte/limite abaixo dos valores estabelecidos na Norma Brasileira ${ }^{16}$ e que eventualmente podem ser encontradas nos laboratórios de ensino e pesquisa, são enumeradas na Tabela 9.

\section{CLASSIFICAÇÃO DOS PERIGOS AO MEIO AMBIENTE}

\section{Classificação de substâncias puras e misturas como Perigoso ao ambiente aquático}

As classes e categorias previstas no GHS ${ }^{15}$ e na Norma Brasileira ${ }^{16}$ para compostos Perigosos ao ambiente aquático, junto com os respectivos elementos de indicação, podem ser encontradas na Tabela 10.

Para classificar substâncias puras como Perigoso ao ambiente aquático - Agudo ou Perigoso ao ambiente aquático - Crônico, devem ser aplicados métodos de ensaios internacionalmente reconhecidos como, por exemplo, os descritos nas OECD Guidelines for the Testing of Chemicals.$^{34}$ Por outro lado, muitas substâncias já são classificadas com respeito aos perigos para o ambiente aquático no Regulamento da $\mathrm{UE}^{14}$ ou pelo National Institute of Technology and Evaluation do Japão. ${ }^{32}$ A Tabela 11 mostra os critérios para atribuição das diversas categorias de perigo. Para a classe Perigoso ao ambiente aquático - Agudo, a classificação é baseada nos dados de toxicidade aguda utilizando a concentração letal para peixes depois de uma exposição de $96 \mathrm{~h}\left(\mathrm{CL}_{50} 96 \mathrm{~h}\right)$, as concentrações efetivas para crustáceos depois de uma exposição de $48 \mathrm{~h}\left(\mathrm{CE}_{50} 48 \mathrm{~h}\right)$ e as concentrações efetivas para algas e outras plantas aquáticas depois de uma exposição de 72 ou 96 h ( CEr $_{50} 72$ h ou 96 h). Na classificação como Perigoso ao ambiente aquático - Crônico, deve-se levar ainda em consideração a degradabilidade e a bioacumulação dessas substâncias. Informações detalhadas a respeito desses fatores podem ser encontradas no GHS ${ }^{15}$ e no Regulamento da UE. ${ }^{14}$

A bioacumulação de uma substância deve, preferencialmente, ser caracterizada pelo fator de bioconcentração (BCF - bioconcentration factor), definido como a razão entre a concentração encontrada no organismo e a concentração presente no ambiente. Na falta de dados sobre o BCF, o mesmo pode ser substituído pelo coeficiente de distribuição octanol - água ( $K_{\mathrm{ow}}$ - octanol-water partition coefficient), definido como a razão da concentração de equilíbrio da substância em octanol e da concentração de equilíbrio da substância em água. ${ }^{14-16} \mathrm{~A}$ classificação nas categorias 2-4 de Perigoso ao ambiente aquático Crônico, somente será necessária se a concentração para a qual não se observam efeitos sobre os organismos aquáticos (NOEC - non observed effect concentration) for $\leq 1 \mathrm{mg} / \mathrm{L} .^{14-16}$

Na classificação como Perigoso ao ambiente aquático - Agudo e Perigoso ao ambiente aquático - Crônico de misturas cujos componentes já são classificados, pode-se usar o método somatório especificado na Tabela 12, com os fatores multiplicativos enumerados na Tabela 13, ou a equação da aditividade (Equação 3 - aditividade para classificação da toxicidade aquática aguda. ${ }^{14,15}$ ). No último caso, a $\mathrm{CL}_{50}$ e/ou os respectivos valores $\mathrm{EC}_{50} \mathrm{e} \mathrm{ECr}_{50}$ são utilizados para calcular os valores $\mathrm{CL}_{50 \mathrm{~m}}, \mathrm{EC}_{50 \mathrm{~m}}$ e ECr $\mathrm{Erm}_{50 \mathrm{~m}}$ da mistura com a Equação 3 . Os valores obtidos com esta Equação permitem a classificação da mistura com os dados enumerados na Tabela 11. De maneira semelhante, pode-se calcular a toxicidade crônica equivalente $\left(\right.$ EqNOEC $\left._{\mathrm{m}}\right)$

Tabela 9. Exemplo de compostos cuja classificação exige, no Regulamento da UE, valores de corte/limite abaixo dos valores aplicados na Norma Brasileira

\begin{tabular}{|c|c|c|c|}
\hline Composto & Classe de perigo & Categoria & $\begin{array}{l}\text { Concentração de corte/limite na classificação } \\
\text { caso-a-caso aplicado no Regulamento da UE }{ }^{14}\end{array}$ \\
\hline Sulfato/cloreto/nitrato/perclorato de níquel(II) & Sensibilização à pele & 1 & $\mathrm{c} \geq 0,01 \%$ \\
\hline Sulfato de dimetilo & Mutagenicidade & 2 & $\mathrm{c} \geq 0.01 \%$ \\
\hline Éter diclorometílico & \multirow{5}{*}{ Carcinogenidade } & $1 \mathrm{~A}$ & $\mathrm{c} \geq 0,001 \%$ \\
\hline Dipropilnitrosamina & & $1 \mathrm{~B}$ & $\mathrm{c} \geq 0,001 \%$ \\
\hline Dimetilnitrosamina & & $1 \mathrm{~B}$ & $\mathrm{c} \geq 0,001 \%$ \\
\hline Fluoreto/cloreto ou sulfato de cádmio(II) & & $1 \mathrm{~B}$ & $\mathrm{c} \geq 0,01 \%$ \\
\hline Cloreto/sulfato/acetato/nitrato ou carbonato de cobalto(II) & & $1 \mathrm{~B}$ & $\mathrm{c} \geq 0,01 \%$ \\
\hline Cloreto de cromilo & \multirow{3}{*}{ TOAE exp. úni.* } & 3 & $0,5 \% \leq \mathrm{c}<5 \%$ \\
\hline Fosfato de tricresilo ou fosfato de tritolila & & 2 & $0,2 \% \leq \mathrm{c}<1 \%$ \\
\hline Dióxido de nitrogênio ou tetraóxido de dinitrogênio & & 3 & $\mathrm{c} \geq 0,5 \%$ \\
\hline Tetra-alquilas de chumbo & \multirow{4}{*}{ TOAE exp. rep..$^{\dagger}$} & 2 & $\mathrm{c} \geq 0,05 \%$ \\
\hline Sulfato/cloreto/nitrato ou perclorato de níquel(II) & & 2 & $0,1 \% \leq \mathrm{c}<1 \%$ \\
\hline Sulfeto de cádmio & & 2 & $0,1 \% \leq \mathrm{c}<1 \%$ \\
\hline Dimetil- ou dietil mercúrio & & 2 & $\mathrm{c} \geq 0,05 \%$ \\
\hline
\end{tabular}

*Toxicidade para órgãos-alvo específicos - Exposição única; ${ }^{\dagger}$ Toxicidade para órgãos-alvo específicos - Exposição repetida. 
Tabela 10. Classes e categorias dos perigos para o meio ambiente com os pictogramas, palavras de advertência e frases de perigo atribuídos ${ }^{14-16}$

\begin{tabular}{|c|c|c|c|c|c|c|c|c|}
\hline \multirow{2}{*}{$\begin{array}{c}\text { Classe } \\
\text { Categoria }\end{array}$} & \multicolumn{3}{|c|}{ Perigoso ao ambiente aquático - Agudo } & \multicolumn{4}{|c|}{ Perigoso ao ambiente aquático - Crônico } & \multirow{2}{*}{$\begin{array}{c}\begin{array}{c}\text { Perigoso à } \\
\text { camada de } \\
\text { ozônio }\end{array} \\
1 \\
\end{array}$} \\
\hline & 1 & 2 & 3 & 1 & 2 & 3 & 4 & \\
\hline Pictograma & & - & - & & & - & - & \\
\hline $\begin{array}{c}\text { Palavra de } \\
\text { advertência }\end{array}$ & Atenção & - & - & Atenção & - & - & - & Atenção \\
\hline $\begin{array}{c}\text { Frase de } \\
\text { perigo }\end{array}$ & $\begin{array}{l}\text { Muito } \\
\text { tóxico para os } \\
\text { organismos } \\
\text { aquáticos }\end{array}$ & $\begin{array}{c}\text { Tóxico para } \\
\text { os organismos } \\
\text { aquáticos }\end{array}$ & $\begin{array}{c}\text { Nocivo para } \\
\text { os organismos } \\
\text { aquáticos }\end{array}$ & $\begin{array}{l}\text { Muito tóxico } \\
\text { para os organis- } \\
\text { mos aquáticos, } \\
\text { com efeitos } \\
\text { prolongados }\end{array}$ & $\begin{array}{c}\text { Tóxico para } \\
\text { os organismos } \\
\text { aquáticos, } \\
\text { com efeitos } \\
\text { prolongados }\end{array}$ & $\begin{array}{c}\text { Nocivo para } \\
\text { os organismos } \\
\text { aquáticos, } \\
\text { com efeitos } \\
\text { prolongados }\end{array}$ & $\begin{array}{l}\text { Pode provocar } \\
\text { efeitos nocivos } \\
\text { prolongados para } \\
\text { os organismos } \\
\text { aquáticos }\end{array}$ & $\begin{array}{l}\text { Provoca danos } \\
\text { à saúde pública } \\
\text { e ao meio } \\
\text { ambiente pela } \\
\text { destruição da } \\
\text { camada de } \\
\text { ozônio }\end{array}$ \\
\hline
\end{tabular}

Tabela 11. Classificação do perigo ao ambiente aquático e da toxicidade aquática crônica segundo a Norma Brasileira ${ }^{16}$

\begin{tabular}{|c|c|}
\hline \multicolumn{2}{|r|}{ Perigoso ao ambiente aquático - Agudo } \\
\hline Categoria & $\mathrm{CL}_{50} 96 \mathrm{~h} / \mathrm{CE}_{50} 48 \mathrm{~h}$ ou $\mathrm{CEr}_{50} 72$ ou $96 \mathrm{~h}$ \\
\hline 1 & $\leq 1 \mathrm{mg} / \mathrm{L}$ \\
\hline 2 & $1<\mathrm{c} \leq 10 \mathrm{mg} / \mathrm{L}$ \\
\hline 3 & $10<\mathrm{c} \leq 100 \mathrm{mg} / \mathrm{L}$ \\
\hline \multicolumn{2}{|r|}{ Perigoso ao ambiente aquático - Crônico } \\
\hline Categoria & $\mathrm{CL}_{50} 96 \mathrm{~h} / \mathrm{CE}_{50} 48 \mathrm{~h}$ ou CEr ${ }_{50} 72$ ou $96 \mathrm{~h}$ \\
\hline $1 *$ & $\leq 1 \mathrm{mg} / \mathrm{L}$ \\
\hline $2^{\dagger}$ & $1<\mathrm{c} \leq 10 \mathrm{mg} / \mathrm{L}$ \\
\hline $3^{\dagger}$ & $10<\mathrm{c} \leq 100 \mathrm{mg} / \mathrm{L}$ \\
\hline $4^{\dagger}$ & $\begin{array}{c}\text { Substâncias que motivam cuidados, mas não permitem } \\
\text { uma classificação segundo critérios formais (p.e. com- } \\
\text { postos pouco solúveis sem toxicidade aquática aguda } \\
\text { que não são rapidamente degradados e com potencial de } \\
\text { bioacumulação) }\end{array}$ \\
\hline \multicolumn{2}{|c|}{ Toxicidade aquática crônica de misturas pela aditividade } \\
\hline Categoria & $\mathrm{EqNOEC}_{\mathrm{m}}$ \\
\hline 1 & $\leq 0,01 \mathrm{mg} / \mathrm{L}$ \\
\hline 2 & $\leq 0,1 \mathrm{mg} / \mathrm{L}$ \\
\hline 3 & $\leq 1,0 \mathrm{mg} / \mathrm{L}$ \\
\hline
\end{tabular}

*Se a substância não for rapidamente degradável e/ou $\log _{10} K_{\mathrm{ow}} \geq 4$. Desconsiderar o valor $\log _{10} K_{\text {ow }}$ quando existir valor de $\mathrm{BCF} \geq 500$, determinado por via experimental; 'Se a substância não for rapidamente degradável e/ou $\log _{10} K_{\text {ow }} \geq 4$. Desconsiderar o valor $\log _{10} K_{\text {ow }}$ quando existir valor de $\mathrm{BCF} \geq$ 500 , determinado por via experimental, e a menos que a toxicidade crônica, NOEC, seja $>1 \mathrm{mg} / \mathrm{L}$.

aplicando-se a Equação 4 - aditividade para classificação da toxicidade aquática crônica ${ }^{14,15}$ e a classificação da mistura é feita segundo os valores mostrados na Tabela 12 .

$$
\frac{\sum c_{i}}{C(E) L_{50_{m}}}=\sum_{n} \frac{c_{i}}{C(E) L_{50_{i}}}
$$

onde: $c_{i}=$ concentração do componente $i$ (percentagemempeso); $C(E) c_{50 i}=C L_{50}, E C_{50}$ ou $E C r_{50}$ para o componente $i$ em $(\mathrm{mg} / \mathrm{L})$; $n=$ número de componentes com $i$ variando de 1 a $n ; C(E) L_{50 m}=$ $C(E) L_{50}$ da parte da mistura para a qual existem dados de ensaio

$$
\frac{\sum c_{i}+\sum c_{j}}{E q N O E C_{m}}=\sum_{n} \frac{C_{i}}{N O E C_{i}}+\sum_{n} \frac{c_{j}}{0,1 \times N O E C_{j}}
$$

Tabela 12. Classificação de misturas como Perigoso ao ambiente aquático Agudo e Perigoso ao ambiente aquático - Crônico, pelo método somatório ${ }^{15,16}$

\begin{tabular}{lc}
\hline Soma da concentração dos componentes & Classificação \\
\hline Categoria $1 \times \mathrm{M}^{*}>25 \%$ & Categoria 1
\end{tabular}

$\left(\mathrm{M}^{*} \times 10 \times\right.$ categoria 1$)+$ categoria $2>25 \%$

Categoria 2

$\left(\mathrm{M}^{*} \times 100 \times\right.$ categoria 1$)+(10 \times$ categoria 2$)+$

Categoria 3 categoria $3>25 \%$

Somente para Perigoso ao ambiente aquático - Crônico

Categoria $1+$ categoria $2+$ categoria $3+$ categoria $4>25 \%$ Categoria 4

*Fator multiplicativo conforme Tabela 13. Fatores multiplicativos para classificação de substâncias classificadas na categoria 1 das classes Perigoso ao ambiente aquático - Agudo ou Perigoso ao ambiente aquático - Crônico pelo método somatório15,1613.

Tabela 13. Fatores multiplicativos para classificação de substâncias classificadas na categoria 1 das classes Perigoso ao ambiente aquático - Agudo ou Perigoso ao ambiente aquático - Crônico pelo método somatório ${ }^{15,16}$

\begin{tabular}{cc}
\hline Valor de $\mathrm{CL}_{50}$ ou $\mathrm{CE}_{50}(\mathrm{mg} / \mathrm{L})$ & Fator multiplicativo $\mathrm{M}$ \\
\hline $0,1<\mathrm{c} \leq 1$ & 1 \\
$0,01<\mathrm{c} \leq 0,1$ & 10 \\
$0,001<\mathrm{c} \leq 0,01$ & 100 \\
$0,0001<\mathrm{c} \leq 0,001$ & 1000 \\
$0,00001<\mathrm{c} \leq 0,0001$ & 10000 \\
\hline
\end{tabular}

onde: $c_{i}=$ concentração do componente $i$ (percentagem em peso) para os componentes rapidamente degradáveis; $c_{j}=$ concentração do componente $j$ (percentagem em peso) para os componentes não rapidamente degradáveis; $N O E C_{i}=N O E C$ (concentração para qual não se observa efeitos) do componente $i$, para os componentes rapidamente degradáveis, em mg/L; NOEC $C_{j}=N O E C$ (concentração para qual não se observa efeitos) do componente $j$, para os componentes não rapidamente degradáveis, em $\mathrm{mg} / \mathrm{L} ; n=$ número de componentes, com $i$ e $j$ a variar de 1 a $n ; E q N O E C_{m}=N O E C$ equivalente da parte da mistura para a qual existem dados de ensaio

\section{Classificação de substâncias puras e misturas como Perigoso à camada de ozônio}

A Tabela 10 também mostra a classe "Perigoso à camada de ozônio", com seus elementos de indicação, definida nas $3^{\mathrm{a}}$ e $4^{\mathrm{a}}$ edições do 
GHS,${ }^{15(c, d)}$ na versão consolidada do Regulamento da UE,${ }^{14}$ publicada em 2011, e na 2a edição da Norma Brasileira, ${ }^{16}$ publicada em 2012. Na classificação como "Perigoso à camada de ozônio", deve ser considerada qualquer substância pura enumerada no Protocolo de Montreal sobre substâncias que empobrecem a camada de ozônio ${ }^{37}$ ou as misturas contendo estes compostos numa concentração somatória maior ou igual a $0,1 \% .^{14,15}$

\section{CONSIDERAÇÕES FINAIS}

É deveras importante que a comunidade envolvida com o uso de produtos químicos, sejam químicos academicamente formados ou outros profissionais que também trabalham com produtos químicos, tenha acesso irrestrito e esclarecido às fontes das normas aqui debatidas. O conhecimento das regras de rotulagem e manuseio permite uma maior segurança na lida com produtos químicos e aceleram as tomadas de decisão em caso de acidentes.

Naturalmente, como o Brasil possui sua própria codificação de regras para o tema, todos devem estudar tal material e avaliar suas minúcias, repensar tais regras e, se possível, melhorar o compêndio das mesmas. Com o passar do tempo, surgem novos materiais que, provavelmente, exigirão novas formas de avaliação, de classificação, de rotulagem, de riscos e de procedimentos de segurança. Um exemplo disso é o caso dos produtos prejudiciais para a camada de ozônio, somente inseridos na Norma Brasileira ${ }^{16}$ durante a preparação desse artigo ou futuramente, os nanomateriais cujos métodos de síntese e purificação ainda não permitem padronizações definitivas e comuns a todos os fabricantes, ${ }^{38}$ acarretando em insegurança na determinação dos seus reais perigos e, assim, fragilizando o aceite dos resultados obtidos em pesquisas pelos consumidores.

Todavia, diferentes profissionais criando padronizações novas para novos materiais tendem a gerar divergências e, assim, as padronizações novas podem acabar formando uma Torre de Babel onde a divergência irá imperar. Como consequência, muito se deve trabalhar para que as regras unificadas sejam universalmente aplicadas e comecem a fazer parte da vida da comunidade desde os tempos das disciplinas escolares e, assim, permitir a avaliação da periculosidade de diversos produtos da maneira mais objetiva possível. No apagar das luzes, dois pontos nunca podem ser esquecidos num sistema padronizado: racionalização e universalização. O primeiro ponto torna o sistema realmente efetivo e o segundo, torna seu uso aplicado a todos os lugares. Em uma sociedade onde a economia e a informação são "globalizadas", nada mais natural que as regras aqui discutidas também o sejam.

\section{AGRADECIMENTOS}

Às Profas. Dras. D. Bianchini e A. J. R. W. A. dos Santos pela revisão ortográfica e gramatical da versão final do artigo. Também devem ser agradecidas as indicações do Assessor sobre a situação legal da implementação do GHS no Brasil, bem como a permissão da Berufsgenossenschaft Rohstoffe und chemische Industrie para utilizar, neste artigo a etiqueta confeccionada com o aplicativo "Gemischrechner" como Figura.

\section{REFERÊNCIAS}

1. Zucco, C.; Quim. Nova 2011, 34, 733.

2. Krätz, O.; Historische chemische Versuche, $4^{\mathrm{a}}$ ed., Aulis Verlag Deubner \& Co KG: Köln, 1997, p. 243.

3. Haustein, M.; Chem. Unserer Zeit 2011, 45, 398.

4. Andréas, H.; Chem. Unserer Zeit 1996, 30, 23.

5. Garcia, E. G.; Bussacos, M. A.; Fischer, F. M.; Ciênc. Saúde Coletiva 2008, 13 (suppl. 2), 2279.
6. Winder, C.; Azzi, R.; Wagner, D.; J. Hazard. Mater. 2005, 125, 29.

7. Lei $N^{o} 7.802$, de 11/07/1989, http://www.planalto.gov.br/ccivil_03/leis/ L7802.htm, acessada em Maio 2012.

8. Decreto ${ }^{\circ}$ 2657, de 03/07/1998, https://www.planalto.gov.br/ccivil_03/ decreto/d2657.htm, acessada em Maio 2012.

9. http://www.cas.org/newsevents/releases/60millionth052011.html, acessada em Maio 2012.

10. Römpp Lexikon Chemie; Falbe, F.; Regitz, M., eds.; $10^{\mathrm{a}}$ ed., Georg Thieme Verlag: Stuttgart. 1996, p. 689.

11. Silk, J. C.; Int. J. Hyg. Environ. Health 2003, 206, 447.

12. Pratt, I. S.; Toxicol. Lett. 2002, 128, 5.

13. Hill Jr., R. H.; J. Chem. Health Saf. 2010, 17, 5.

14. Regulamento (CE) no 1272/2008 do Parlamento Europeu e do Conselho de 16/12/2008, publicado no Jornal Oficial da União Europeia, de 31/12/2008, p. 1-1355, http://eur-lex.europa.eu/LexUriServ/LexUriServ. do?uri=OJ:L:2008:353:0001:1355:pt:PDF, acessada em Maio2012; versão consolidada, http://eur-lex.europa.eu/LexUriServ/LexUriServ. do?uri=CONSLEG:2008R1272:20110419:PT:PDF, acessada em Maio 2012.

15. Globally Harmonized System of Classification and Labelling of Chemicals (GHS), $1^{\text {st }}$ ed., United Nations: New York, 2003, http://www.unece. org/trans/danger/publi/ghs/ghs_rev00/00files_e.html, acessada em Março 2012; Globally Harmonized System of Classification and Labelling of Chemicals (GHS), $2^{\text {nd }}$ ed., United Nations: New York, 2007, http:// www.unece.org/trans/danger/publi/ghs/ghs_rev02/02files_e.html, acessada em Maio 2012; Globally Harmonized System of Classification and Labelling of Chemicals (GHS), $3^{\text {rd }}$ ed., United Nations: New York, 2009, http://www.unece.org/trans/danger/publi/ghs/ghs_rev03/03files_e.html, acessada em Maio 2012; Globally Harmonized System of Classification and Labelling of Chemicals (GHS), $4^{\text {th }}$ ed., United Nations: New York, 2011, http://www.unece.org/trans/danger/publi/ghs/ghs_rev04/04files_e. html, acessada em Maio 2012.

16. Produtos químicos - Informações sobre segurança e meio ambiente, partes 1-4, Norma Brasileira ABNT NBR 14725, Associação Brasileira de Normas Técnicas, ed.; Rio de Janeiro, 2009, http://www.abntcatalogo. com.br, procurar a Norma pelo número, acessada em Maio 2012; $2^{\mathrm{a}}$ ed., 2012, acessada em Junho 2012.

17. Das Neue Einstufungs- und Kennzeichungssystem für Chemikalien nach GHS - kurz erklärt -, Koch, J.; Stark, C.; eds.; Umweltbundesamt, Dessau-Roßlau, 2009, http://www.umweltdaten.de/publikationen/ fpdf-1/3973.pdf, acessada Janeiro 2013.

18. O que é GHS? - Sistema harmonizado globalmente para a classificação e rotulagem de produtos químicos, Associação Brasileira da Indústria Química, Departamento de Assuntos Técnicos (ed.); ABIQUIM/DETEC: São Paulo, 2005, http://www.anvisa.gov.br/reblas/reblas_public_ manual_ghs.pdf, acessada em Maio 2012.

19. GHS pictogramas, UNECE, http://www.unece.org/trans/danger/publi/ ghs/pictograms.html, acessada em Maio 2012.

20. Gemischrechner der Berufsgenossenschaft Rohstoffe und chemische Industrie, https://ssl.gischem.de/gemischrechner/index.htm, acessada em Agosto 2012.

21. Decreto sem número de 26/06/2007, https://www.planalto.gov.br/ ccivil_03/_ato2007-2010/2007/dnn/dnn11288.htm, acessada em Maio 2012.

22. http://www.unece.org/trans/danger/publi/ghs/implementation_e. html\#c25750, acessada em Maio 2012.

23. Norma Regulamentadora NR 26 - Sinalização de Segurança, Ministério do Trabalho e Emprego, http://portal.mte.gov.br/data/files/8A7C816A3 1190C1601312A0E15B61810/nr_26.pdf, acessada em Agosto 2012.

24. Ministério do Trabalho e Emprego; Portaria No. 229 de 24/05/2011, http://portal.mte.gov.br/data/files/8A7C812D302E6FAC013031C980D 74AC9/p_20110524_229.pdf, acessada em Maio 2012.

25. National Institute of Technology and Evaluation - NITE; Technical 
Guidance Document on GHS Classification, Tóquio, 2005, http://www safe.nite.go.jp/english/pdf/ghs_guidance_e.pdf, acessada em Maio 2012.

26. National Institute of Technology and Evaluation - NITE; GHS Classification Manual, Tóquio, 2005, http://www.safe.nite.go.jp/english/pdf/ ghs_manual_e.pdf; acessada em Maio 2012.

27. National Institute of Technology and Evaluation - NITE; GHS Classification Guidance for the Japanese Government, $2^{\text {nd }}$ ed., Tóquio, 2010, http://www.meti.go.jp/policy/chemical_management/int/files/ghs/ GHS_guidance_2nd_rivised/GHS\%20Classification\%20Guidance $\% 20$ for\%20government\%202nd.pdf, acessada em Maio 2012.

28. National Institute of Technology and Evaluation - NITE; GHS Classification Guidance for Enterprises, $2^{\text {nd }}$ ed., Tóquio, 2010, http://www.meti. go.jp/policy/chemical_management/int/files/ghs/GHS_guidance_2nd_ rivised/GHS\%20Classification\%20Guidance\%20for\%20enterprise $\% 20$ 2nd.pdf, acessada em Maio 2012.

29. National Institute of Technology and Evaluation - NITE; Guidance on a Consumer Product Risk Assessment for GHS Labelling, Tóquio, 2008, http://www.safe.nite.go.jp/english/ghs/consumer_product.html, acessada em Maio 2012.

30. International Organization for Standardization; ISO 101156:2010: Gases and gas mixtures -- Determination of fire potential and oxidizing ability for the selection of cylinder valve outlets, Genebra, 2010; apud ref. 15; http://www.iso.org/iso/iso_catalogue/catalogue_ics/catalogue_detail_ics. htm?csnumber=44817, acessada em Maio 2012.
31. United Nations; Recommendations on the Transport of Dangerous Goods - Manual of Tests and Criteria, $5^{\text {th }}$ ed.; United Nations: New York, 2009; http://www.unece.org/fileadmin/DAM/trans/danger/publi/ manual/Rev5/English/ST-SG-AC10-11-Rev5-EN.pdf, acessada em Maio 2012.

32. http://www.safe.nite.go.jp/english/ghs_index.html\#results, acessada em Maio 2012.

33. United Nations; Recommendations on the Transport of Dangerous Goods - Model Regulations, $17^{\text {th }}$ ed.; United Nations: New York, 2011, http://www.unece.org/trans/danger/publi/unrec/rev17/17files_e.html, acessada em Maio 2012.

34. Organisation for Economic Co-operation and Development; OECD Guidelines for the Testing of Chemicals, http://www.oecd.org/env/ehs/ testing/oecdguidelinesforthetestingofchemicals.htm, acessada Janeiro 2013.

35. Morita, T.; Morikawa, K.; Ind. Health 2011, 49, 559.

36. Morita, T.; Hayashi, M.; Nakajima, M.; Tanaka, N.; Tweats, D. J.; Morikawa, K.; Sofuni, T.; Regul. Toxicol. Pharmacol. 2009, 55, 52.

37. Montreal Protocol on Substances That Deplete the Ozone Layer; http:// ozone.unep.org/Publications/MP_Handbook/Section_1.1_The_Montreal_Protocol/, acessada em Maio 2012.

38. Protocol for the characterization of single-wall carbon nanotube material quality, http://dx.doi.org/10.1016/j.carbon.2004.03.038, acessada em Maio 2012. 